\title{
How to Improve Reprocessing of Flexible Endoscopes Nationwide? Data from the German Colorectal Cancer Screening Program
}

\author{
Eckhart Fröhlich, ${ }^{1}$ Ottmar Leiß, ${ }^{2}$ and Reinhold Muller ${ }^{3}$ \\ ${ }^{1}$ Innere Klinik mit Gastroenterologie, Karl-Olga-Krankenhaus, Hackstraße 61, 70190 Stuttgart, Germany \\ ${ }^{2}$ Gastroenterologische Gemeinschaftspraxis, Bahnhofsplatz 2, 55116 Mainz, Germany \\ ${ }^{3}$ School of Public Health, Tropical Medicine and Rehabilitation, James Cook University, Townsville, QLD 4811, Australia \\ Correspondence should be addressed to Eckhart Fröhlich; eckhart.froehlich@gmx.de
}

Received 13 July 2012; Accepted 11 September 2012

Academic Editors: C. Boselli, B. Braden, A. Kahokehr, A. Maleddu, H. Sarel, and D. Stoyanov

\begin{abstract}
Copyright (C) 2013 Eckhart Fröhlich et al. This is an open access article distributed under the Creative Commons Attribution License, which permits unrestricted use, distribution, and reproduction in any medium, provided the original work is properly cited.
\end{abstract}

\begin{abstract}
Background and Aims. International studies revealed prevalences of around $50 \%$ of microbiological contaminations in reprocessed flexible endoscopes. In Germany a system was installed where the qualification for refund for colonoscopies was made conditional on successfully passing twice annually a microbiological surveillance test of reprocessed endoscopes. This study is an implementation and outcome evaluation as well as a general discussion of the quality assessment assurance in colonoscopy in Germany. Methods. German data from 2003-2008 were analysed: number of endoscopic units performing therapeutic and/or screening colonoscopies; results of all microbiological surveillance tests of reprocessing quality; number of failed surveillance tests and retests; number of qualifications for refund from the public health system cancelled due to repeated failure of microbiological surveillance tests. Results. After the introduction of the quality assessment assurance, the percentage of failed microbiological surveillance tests dropped significantly and steadily from close to $17 \%$ to below $5 \%$. Conclusions. This study evidences (1st) the successful implementation of the quality assessment assurance in Germany and (2nd) a substantial improvement in the quality of reprocessing flexible endoscopes achieved by these measures.
\end{abstract}

\section{Introduction}

Flexible endoscopes invariably become contaminated with microorganisms during clinical use. With the more widespread use of flexible endoscopy 30 years ago, nosocomial infections associated with oesophago-gastroduodenoscopy, colonoscopy, endoscopic retrograde cholangiopancreaticography (ERCP), or bronchoscopy were observed and described in the literature [1-9]. A survey in the 70ies yielded an estimated risk of 1 per 10,000 endoscopic examinations (oesophagogastroduodenoscopies und colonoscopies) [10]. More recently, optimistic estimates suggest a lower risk of 1 in 1.8 million [11] or 1 in 5 million procedures [12] given millions of endoscopic examinations worldwide. Data from the late nineteen-seventies report an infection rate of 0.74 and $0.93 \%$ following endoscopic retrograde cholecystopancreaticoscopy (ERCP) $[7,8,13]$. The risk for transmission of, for example, Helicobacter pylori has been considered to be likely around of 2-3 per 1000 oesophagogastroduodenoscopies [14-16]. The problem of possible infections originating from endoscopic examinations has been controversially discussed by the media, that is, in Germany [17] and the US [18]. In Germany, this culminated in the repeated statement of a notable hygienist that he himself refrained from endoscopic examinations due to the risk of infection [19].

To minimize the risk of infection transmission via endoscopes many gastroenterological and hygienic societies worldwide developed national guidelines for reprocessing flexible endoscopes and endoscopic accessories [20-35]. However, implementation of these guidelines in clinical practice and outcome are not evaluated at all. Only small surveys based on questionnaires [36-44] are available, hard data on the effect of national reprocessing guidelines on reprocessing quality are still lacking. 
The situation in Germany is different from other countries. In 2002, based on the results of the HYGEA study [45] confirming similar studies in other countries [22, 46] and a comparison of international guidelines for reprocessing flexible endoscopes [27] the commission for hospital hygiene and disease prevention at the Robert Koch institute, the German analogue to the Centers for Disease Control (CDC) published an evidence-based guideline for reprocessing flexible endoscopes and endoscopic accessories [47]. In addition, a national colorectal cancer screening program via colonoscopy was initiated in autumn 2002. Before nationwide implementation of this screening program a quality assurance agreement was established by the Kassenärztliche Bundesvereinigung (KBV) and the stakeholder of the public health insurances to ensure that screening colonoscopy will be performed safely and without risk for the screened patient. According to this quality assurance agreement [48] both qualification indicators for the performing gastroenterologist were defined (see Section 4) and monitoring of colonoscope reprocessing by microbiological cultures was implemented. Certification to participation in the colorectal cancer screening program was given by the local KV only after documented fulfilling of these qualification requirements and financial funding for screening colonoscopy was coupled to compliance with the quality indicators and negative surveillance cultures of reprocessed colonoscopies. Under coordination by the central KBV and supervision and control by local Kassenärztliche Vereinigungen $(\mathrm{KV})$ in the different states of the Federal Republic of Germany a nationwide system was established with certificated microbiological laboratories performing two times per year microbiological surveillance cultures from swabs from the tip of the colonoscope, from flushing solution of disinfected channels of the instrument, and from water bottle solution of the optic flushing system.

The present study is an implementation and outcome evaluation of the German quality assurance agreement with the specific aims to analyse surveillance culture data from 2002 to 2008 in detail and to assess whether linking reprocessing quality indicators to funding of colonoscopy will improve colonoscope reprocessing quality in the long run.

\section{Materials and Methods}

The following nationwide data, per year and per association of statutory health insurance physicians (in German: Kassenärztliche Vereinigung $(\mathrm{KV})$ ), were made available through the framework of the quality assurance agreement for the time period of 2003 to 2008: the number of endoscopic units performing therapeutic and/or screening colonoscopies within each $\mathrm{KV}$, the results of all microbiological surveillance tests of reprocessed endoscopic units (two per year per unit), the number of failed surveillance tests and failed retests, and the number of qualifications for refund from the public health system cancelled due to repeated failure of microbiological surveillance tests. All surveillance tests were conducted by independent, accredited microbiological institutes/laboratories.

The frequencies of actually performed hygiene surveillance tests per year were expressed as a percentage of the tests prescribed by the assurance system, that is, $100 \%$ are reached when two tests per year were conducted per endoscopic unit. The frequencies of failed microbiological surveillance tests per year (i.e., the number of necessary retests) were expressed as a percentage of the number of actually conducted routine surveillance tests. The frequencies of repeated failure of microbiological surveillance tests per year were also expressed as a percentage of the number of actually conducted initial routine surveillance tests. The frequencies of qualifications for refund from the public health system cancelled due to repeated failure of microbiological surveillance tests were listed as raw numbers.

Analyses of variance for repeated measurements were used to statistically assess the time trends of the above detailed percentages. An overall alpha level of 5\% was used. Pairwise comparisons between consecutive years were analysed by means of paired $t$-tests where a Bonferroni correction for multiple testing was applied.

\section{Results}

The time trends from 2003 to 2008 of the following key microbiological performance parameters are detailed in Table 1:

(1) The number of endoscopy units accredited in Germany for therapeutic and/or preventive colonoscopies.

(2) Percentages of actually performed surveillance tests (out of those prescribed by the quality assurance agreement). Since some associations of statutory health insurance physicians did not provide data for all years, two rows of data are presented: all available information (here the number of reporting associations may differ over the years) and complete information only (only those associations included that reported data for all years of the study period). The latter formed the basis for statistical tests.

(3) Percentages of failed microbiological surveillance tests out of all conducted tests. Again two rows are displayed: for all information available and for complete series only.

(4) Percentages of repeated failures of microbiological tests out of all conducted initial tests. Again two rows are displayed: for all information available and for complete series only.

(5) The number of qualifications for refund from the public health system cancelled due to repeated failure of microbiological tests.

The time trend of percentages of conducted surveillance tests of all KV's with complete data over the whole study period $(n=11)$ are depicted in Figure 1 . The overall trend is statistically significant $(P<0.001)$. Consecutive pairwise comparisons only reveal a significant change between 2003 and 2004. The time trend of percentages of failed tests (out of conducted tests) of all KV's with complete data $(n=10)$ is shown in Figure 2 . The overall trend is statistically significant $(P<0.001)$. Consecutive pairwise comparisons reveal 
TABLE 1: Time trends of key microbiological performance data in endoscopy in Germany from 2003 to 2008.

\begin{tabular}{|c|c|c|c|c|c|c|}
\hline & 2003 & 2004 & 2005 & 2006 & 2007 & 2008 \\
\hline Accredited endoscopic units & 1695 & 2176 & 2645 & 2567 & 2583 & 2476 \\
\hline $\begin{array}{l}\text { Percentages of conducted surveillance tests: } \\
\text { all information used }\end{array}$ & $56.0 \%(13)$ & $94.9 \%(14)$ & $97.4 \%(17)$ & $93.1 \%(16)$ & $97.6 \%(17)$ & $96.4 \%(16)$ \\
\hline $\begin{array}{l}\text { Percentages of conducted surveillance tests: } \\
\text { only complete information used }\end{array}$ & $58.5 \%(11)$ & $94.2 \%(11)$ & $96.8 \%(11)$ & $98.5 \%(11)$ & $96.3 \%(11)$ & $94.8 \%(11)$ \\
\hline $\begin{array}{l}\text { Percentages of failed tests: } \\
\text { all information used }\end{array}$ & $16.6 \%(12)$ & $9.7 \%(14)$ & $5.1 \%(16)$ & $5.1 \%(16)$ & $3.7 \%(17)$ & $4.2 \%(16)$ \\
\hline $\begin{array}{l}\text { Percentages of failed tests: } \\
\text { only complete information used }\end{array}$ & $16.5 \%(10)$ & $9.9 \%(10)$ & $6.7 \%(10)$ & $5.8 \%(10)$ & $3.4 \%(10)$ & $5.6 \%(10)$ \\
\hline $\begin{array}{l}\text { Percentages of repeated failures: } \\
\text { all information used }\end{array}$ & $0.9 \%(11)$ & $1.4 \%(14)$ & $0.8 \%(14)$ & $0.2 \%(16)$ & $0.3 \%(17)$ & $0.2 \%(16)$ \\
\hline $\begin{array}{l}\text { Percentages of repeated failures: } \\
\text { only complete information used }\end{array}$ & $0.8 \%(9)$ & $0.9 \%(9)$ & $0.4 \%(9)$ & $0.1 \%(9)$ & $0.1 \%(9)$ & $0.1 \%(9)$ \\
\hline $\begin{array}{l}\text { Number of accreditations cancelled due to } \\
\text { repeated failure }\end{array}$ & 5 & 3 & 17 & 2 & 9 & 6 \\
\hline
\end{tabular}

Stated are the raw numbers and percentages as indicated. In brackets the numbers of the reporting associations of statutory health insurance physicians are given.

significant changes between 2003 and 2004 and between 2004 and 2005. The overall time trend of repeated failures $(n=9)$ is significant $(P<0.01)$. Consecutive pairwise comparisons revealed only between 2004 and 2005 a significant result.

\section{Discussion}

Since colorectal cancer is one of the main cancers in Western societies accounting for more than 50.000 deaths each year in the United States [49] and more than 30.000 deaths each year in Germany [50], colonoscopy as the gold standard for early detection of adenomas and carcinomas in symptom-free individuals is considered as a mass screening tool to reduce incidence and mortality from colorectal cancer by detecting and removing potential precursor lesions.

4.1. General Remarks: Quality Management of Screening Colonoscopy. Several studies have shown that colonoscopic polypectomy reduces colorectal cancer incidence [51-60]. Furthermore, screening with colonoscopy is costeffective compared to other screening strategies $[61,62]$.

However, colonoscopy is an invasive procedure and not without risk. Therefore, those performing this test have to be well trained and experienced. In addition, in order to remove public concerns regarding the risk of infection transmission, reprocessing of the screening instrument, the flexible colonoscope has to be in accordance with recent evidence-based guidelines [20-35].

Data on the process quality and the incidence of acute complications and data on the diagnostic yield of screening colonoscopy of the German colorectal cancer screening program were recently published $[63,64]$.

In addition, Germany was the first country worldwide having realized continuous monitoring of colonoscope reprocessing by microbiological surveillance cultures of reprocessed endoscopes.

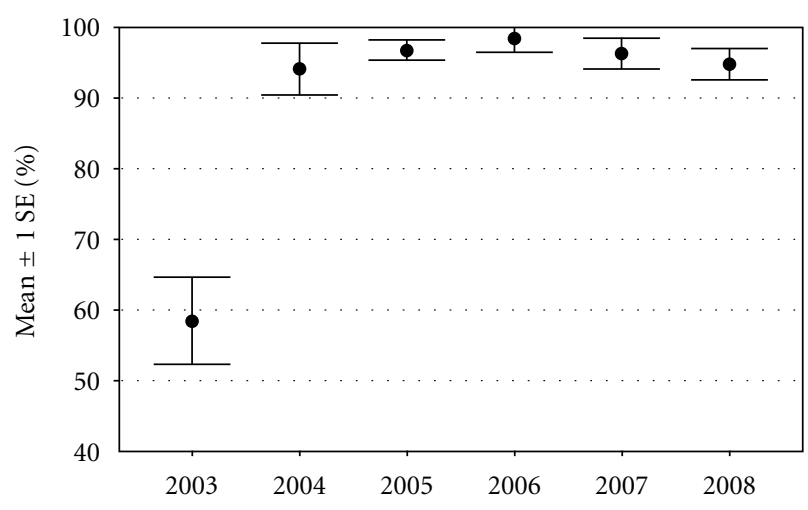

FIGURE 1: Time trend of conducted surveillance tests 2003-2008.

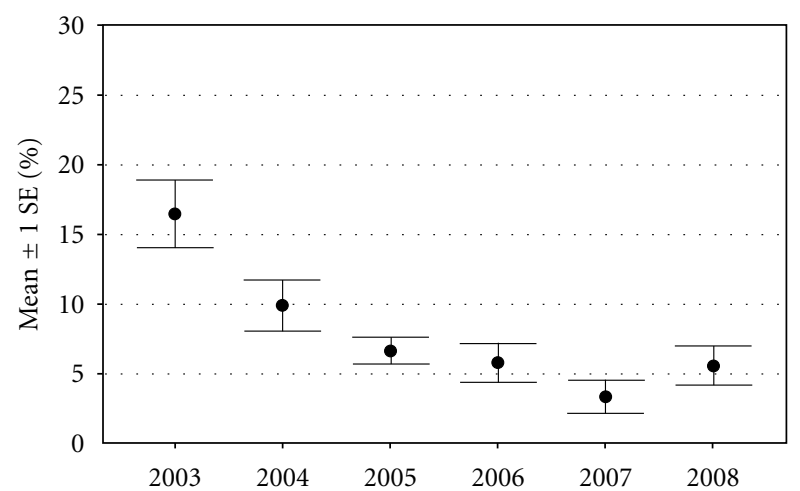

FIGURE 2: Time trend of failed microbiological surveillance tests.

In this paper, we present the data on the implementation and outcome of the German nationwide continuous monitoring of colonoscope reprocessing by microbiological surveillance cultures of reprocessed endoscopes. 
4.2. The German System: Implementation of a Quality Control Program for Endoscope Reprocessing. In order to establish and maintain high-quality standards for screening colonoscopy the public health insurances and the KBV, the main players of the ambulance health system in Germany [65-67], arranged a quality assurance agreement before starting the German colorectal screening program by colonoscopy. According to this agreement [48] the following quality indicators for the performing gastroenterologist were defined as a marker for experience-a minimal number of more than 200 colonoscopies and 20 polypectomies per year-as a marker for performance-(electronic or videoprint) documentation of the ileocoecal valve or the terminal ileum and-as a marker for staff performance/equipment reprocessing quality-negative surveillance cultures of disinfected colonoscopes two times per year. The central issue in this quality management program consists in payment for performance and continuous documentation of the quality indicators for colonoscopy mentioned above. Each gastroenterologist, performing endoscopies in his office and fulfilling the qualification requirements, can participate in the German colorectal cancer screening program.

For a nationwide colonoscopy screening program, availability of an experienced gastroenterologist as well as minimizing problems concerning infection risk are crucial steps for acceptance of the screening program. Thus, the German colorectal cancer screening program was coupled and coordinated with a quality assurance agreement implementing outcome monitoring of endoscope reprocessing.

The present analysis is based on the collected data of this quality control program. Completeness and quality of the data needs critical comments. In 2003, the first year of implementation of this control system, surveillance cultures were not performed twice a year but only once a year. For the years 2003 and 2004 in several federal states only limited data were available, collection was done in retrospective and completeness of the data was questionable. Thus, in general data quality and completeness are somewhat limited for the first two years, but become valid in 2005 and the following years.

4.3. German and International Guidelines in Endoscope Reprocessing: Do We Need Surveillance Cultures? The German guideline for reprocessing flexible endoscopes published in 2002 [26] was the first evidence-based guideline for scope reprocessing and was based on a profound literature review comparing international guidelines for endoscope reprocessing prepared by a working group [27] and the results of a large study on hygiene in endoscopy performed in the area of Munich in 2000 [45]. One and a half year later, several gastroenterological, microbiological, and hygienic societies in the United States published a similar evidence-based multisociety guideline [68].

One of the most important differences of these two guidelines is the answer to the problem whether microbiological surveillance cultures of reprocessed endoscopes should be recommended or not. It is absolutely correct, that no data exist demonstrating that regular microbiological surveillance cultures of endoscope reprocessing decrease the risk for infection transmission during endoscopy. Thus, the interpretation of the multisociety guideline [68] and other authors [69] that the value of regular microbiological surveillance cultures of reprocessing is an "unresolved issue" is principally correct. In accordance with this statement microbiological controls of endoscope reprocessing quality are not performed in the United States [49]. In recent years, however, usefulness of surveillance cultures is mentioned more often in the United States [37, 40, 44, 69].

In contrast to the multisociety guideline [68] and considering the poor compliance with hygienic recommendations and variability in implementation $[70,71]$ the German guideline recommended regular surveillance cultures of endoscope reprocessing [26]. The recent European guideline for endoscope reprocessing, published in 2007 [24], also recommended microbiological controls of endoscope reprocessing quality.

The experience of smaller studies from Germany [72, 73], the results of the former nationwide study [74], and the present update reinforce the hypothesis underlying the German RKI guideline that measurement and feedback of reprocessing quality will help to implement reprocessing procedures in accordance with present guidelines. In other words and from a quality management point of view: feedback of reprocessing outcome quality enhances the process quality and compliance with reprocessing guidelines which in turn vice versa affects outcome quality.

4.4. Process Quality or Outcome Quality of Reprocessing Complex Medical Devices? The question whether we should focus on process quality or outcome quality of reprocessing flexible endoscopes is still a matter of debate. Although standardized reprocessing is possible in special washer-disinfectors using automatic single channel cleaning with enzymatic cleaners and programmed disinfection with glutaraldehyde at higher temperature [75], only microbiological controls of reprocessing quality are able to detect equipment defects of flexible endoscopes (such as perforation of internal channels) which affect the outcome of the reprocessing process and which would be without surveillance cultures only recognized in working ups of nosocomial infection outbreaks [76].

4.5. Summary and Conclusions. The quality assurance agreement for screening colonoscopy in Germany in 2002 [58] improved colonoscope reprocessing quality significantly. After implementation a quality control system for colonoscope reprocessing in ambulance offices the rate of positive surveillance cultures from reprocessed endoscopes dropped from $50 \%$ of failed tests observed before the introduction in $2000-2001$ to $17,7 \%$ in 2003 and to $10,1 \%$ in 2004 and reached a plateau of under $5 \%$ in 2008 . Thus, the ethical principle that a screening procedure, such as a screening colonoscopy should be without risk of infection transmission, seems nearly fulfilled.

The question whether monitoring endoscope reprocessing by regular microbiological surveillance cultures will reduce the infection transmission during endoscopy cannot 
yet be answered by the present study. However, our data strongly favor regular surveillance cultures as an important catalyzer for implementation and adherence to national endoscope reprocessing guidelines and for improvement of reprocessing quality. So in order to reduce infection transmission by endoscopy, we recommend that other countries considering implementation of screening colonoscopy should also consider implementation of outcome monitoring of endoscope reprocessing.

\section{Conflict of Interests}

The authors declare that they have no conflict of interests.

\section{Authors' Contribution}

E. Fröhlich: study concept; acquisition of data, O. Leiß: critical revision of the paper, and R. Muller: statistical analysis, interpretation of data, and drafting the paper.

\section{Acknowledgment}

The authors thank the Kassenärztliche Bundesvereinigung Berlin, Germany for contribution of the referred data.

\section{References}

[1] D. Schembre and D. J. Bjorkman, "Review article: endoscopyrelated infections," Alimentary Pharmacology and Therapeutics, vol. 7, no. 4, pp. 347-355, 1993.

[2] G. Ayliffe, "Nosocomial infections associated with endoscopy," in Hospital Epidemiology and Infection Control, G. Mayhall, Ed., pp. 881-895, Lippincott, Williams \& Wilkins, Philadelphia, Pa, USA, 2nd edition, 1999.

[3] O. Leiß, "Infektionsrisiken in der Endoskopie: die Rolle der Endoskopaufbereitung und -überprüfung," Hygiene \& Medizin, vol. 27, pp. 285-296, 2002.

[4] B. H. O'Connor, J. R. Bennett, and J. G. Alexander, "Salmonellosis infection transmitted by fibreoptic endoscopes," The Lancet, vol. 2, no. 8303, pp. 864-866, 1982.

[5] G. G. Birnie, E. M. Quigley, and G. B. Clements, "Endoscopic transmission of hepatitis B virus," Gut, vol. 24, no. 2, pp. 171-174, 1983.

[6] D. M. Dwyer, E. G. Klein, and G. R. Istre, "Salmonella newport infections transmitted by fiberoptic colonoscopy," Gastrointestinal Endoscopy, vol. 33, no. 2, pp. 84-87, 1987.

[7] J. I. Allen, M. O'Connor Allen, and M. M. Olson, "Pseudomonas infection of the biliary system resulting from use of a contaminated endoscope," Gastroenterology, vol. 92, no. 3, pp. 759-763, 1987.

[8] D. C. Classen, J. A. Jacobson, J. P. Burke, J. T. Jacobson, and R. Scott Evans, "Serious pseudomonas infections associated with endoscopic retrograde cholangiopancreatography," The American Journal of Medicine, vol. 84, no. 3, pp. 590-596, 1988.

[9] M. J. Struelens, F. Rost, A. Deplano et al., "Pseudomonas aeruginosa and Enterobacteriaceae bacteremia after biliary endoscopy: an outbreak investigation using DNA macrorestriction analysis," American Journal of Medicine, vol. 95, no. 5, pp. 489-498, 1993.
[10] S. E. Silvis, O. Nebel, G. Rogers, C. Sugawa, and P. Mandelstam, "Endoscopic complications. Results of the 1974 American Society for Gastrointestinal Endoscopy Survey," Journal of the American Medical Association, vol. 235, no. 9, pp. 928-930, 1976.

[11] S. M. Mühldorfer, G. Kekos, E. G. Hahn, and C. Ell, "Complications of therapeutic gastrointestinal endoscopy," Endoscopy, vol. 24, no. 4, pp. 276-283, 1992.

[12] P. Frühmorgen, "Komplikationen bei endoskopischen Untersuchungen (Art, Häufigkeit, Verhütung und Behandlung)," in Gastroenterologische Endoskopie-Ein Leitfaden Zur Diagnostik Und Therapie, P. Frühmorgen, Ed., pp. S56-S66, Springer, Berlin, Germany, 4th edition, 1999.

[13] M. B. Kimmey, D. A. Burnett, D. A. Carr-Locke et al., "Transmission of infection by gastrointestinal endoscopy. Technology Assessment Position Paper," Gastrointestinal Endoscopy, vol. 39, pp. 885-888, 1993.

[14] W. Langenberg, E. A. J. Rauws, J. H. Oudbier, and G. N. J. Tytgat, "Patient-to-patient transmission of Campylobacter pylori infection by fiberoptic gastroduodenoscopy and biopsy," Journal of Infectious Diseases, vol. 161, no. 3, pp. 507-511, 1990.

[15] T. Akamatsu, K. Tabata, M. Hironga, H. Kawakami, and M. Uyeda, "Transmission of Helicobacter pylori infection via flexible fiberoptic endoscopy," American Journal of Infection Control, vol. 24, no. 5, pp. 396-401, 1996.

[16] M. Nürnberg, H. J. Schulz, H. Rüden, and K. Vogt, "Do conventional cleaning and disinfection techniques avoid the risk of endoscopic Helicobacter pylori transmission?" Endoscopy, vol. 35, no. 4, pp. 295-299, 2003.

[17] H.-P. Werner, M. Staritz, and H. S. Füeßl, "Expertendiskussion: infektionen via Endoskop?" Münch Med Wschr, vol. 136, pp. 22-226, 1994.

[18] L. F. Muscarella, "Dear Los Angeles Times: the risk of disease transmission during gastrointestinal endoscopy," Gastroenterology Nursing, vol. 27, no. 6, pp. 271-278, 2004.

[19] H.-P. Werner, "Ein aufgeklärter patient-ein Albtraum," Hygiene \& Medizin, vol. 28, pp. 273-275, 2003.

[20] AWMF-Leitlinie Nr. 029/008, Hygiene in Klinik Und Praxis, 3. Auflage, mhp, Wiesbaden, Germany, 2004.

[21] BSG Guidelines for Decontamination of Equipment for Gastrointestinal Endoscopy, "The Report of a Working Party of the British Society of Gastroenterology Endoscopy Committee," 2008, http://www.touchgastroenterology.com/guidelines/guidelines-decontamination-equipment-gastrointestinal-endoscopy.

[22] R. J. Cheung, D. Ortiz, and A. J. DiMarino Jr., "Gl endoscopic reprocessing practices in the United States," Gastrointestinal Endoscopy, vol. 50, no. 3, pp. 362-368, 1999.

[23] A. J. DiMarino, T. Gage, J. Leung et al., "American Society for Gastrointestinal Endoscopy Position Statement. Reprocessing of flexible gastrointestinal endoscopes," Gastrointestinal Endoscopy, vol. 43, pp. 540-545, 1996.

[24] U. Beilenhoff, C. S. Neumann, J. F. Rey, H. Biering, R. Blum, and V. Schmidt, "ESGE-ESGENA guideline for quality assurance in reprocessing: microbiological surveillance testing in endoscopy," Endoscopy, vol. 39, no. 2, pp. 175-181, 2007.

[25] U. Heudorf and M. Exner, "German guidelines for reprocessing endoscopes and endoscopic accessories: guideline compliance in Frankfurt/Main, Germany," Journal of Hospital Infection, vol. 64, no. 1, pp. 69-75, 2006. 
[26] KRINKO Kommission für Krankenhaushygiene und Infektionsprävention beim Robert Koch Institut, "Anforderungen der Hygiene bei der Aufbereitung flexibler Endoskope und endoskopischen Zusatzinstrumentariums," Bundesgesundheitsblatt, Gesundheitsforschung, Gesundheitsschutz, vol. 45, pp. 395-411, 2002.

[27] O. Leiß, U. Beilenhoff, L. Bader et al., "Leitlinien zur Aufbereitung flexibler Endoskope und endoskopischen Zusatzinstrumentariums im internationalen Vergleich," Zeitschrift für Gastroenterologie, vol. 40, pp. 531-542, 2002.

[28] J. W. Leung, "Reprocessing of flexible endoscopes," in Proceedings of the 11th Asian Pacific Congress of Gastroenterology and the 8th Asian Pacific Congress of Digestive Endoscopy, pp. 10-14, Hong Kong, China, March 2000, Journal of Gastroenterology \& Hepatology, 15, supplement: G73-G77, 2000.

[29] L. F. Muscarella, "Inconsistencies in endoscope-reprocessing and infection-control guidelines: the importance of endoscope drying," American Journal of Gastroenterology, vol. 101, no. 9, pp. 2147-2154, 2006.

[30] D. B. Nelson and L. F. Muscarella, "Current issues in endoscope reprocessing and infection control during gastrointestinal endoscopy," World Journal of Gastroenterology, vol. 12, no. 25, pp. 3953-3964, 2006.

[31] S. Osborne, S. Reynolds, N. George, F. Lindemayer, A. Gill, and M. Chalmers, "Challenging endoscopy reprocessing guidelines: a prospective study investigating the safe shelf life of flexible endoscopes in a tertiary gastroenterology unit," Endoscopy, vol. 39, no. 9, pp. 825-830, 2007.

[32] W. A. Rutala and D. J. Weber, "Reprocessing endoscopes: United States perspective," Journal of Hospital Infection, vol. 56, no. 2, pp. S27-S39, 2004.

[33] SHEA Position Paper, D. B. Nelson, W. R. Jarvis, W. A. Rutala et al., "Society for Healthcare Epidemiology of America. Multisociety guideline for reprocessing flexible gastrointestinal endoscopes," Infection Control and Hospital Epidemiology, vol. 24, pp. 532-527, 2003.

[34] R. Systchenko, B. Marchetti, J. N. Canard et al., "Guidelines of the French Society of Digestive Endoscopy: recommendations for setting up cleaning and disinfection procedures in gastrointestinal endoscopy," Endoscopy, vol. 32, no. 10, pp. 807-818, 2000.

[35] M. Wilkinson, N. Simmons, M. Bramble et al., "Report of the working party of the endoscopy committee of the British Society of Gastroenterology on the reuse of endoscopic accessories," Gut, vol. 42, no. 2, pp. 304-306, 1998.

[36] E. Brullet, J. A. Ramirez-Armengol, R. Campo et al., "Cleaning and disinfection practices in digestive endoscopy in Spain: results of a National Survey," Endoscopy, vol. 33, no. 10, pp. 864-868, 2001.

[37] J. R. Cronmiller, D. K. Nelson, G. Salman et al., "Antimicrobial efficacy of endoscopic disinfection procedures: a controlled, multifactorial investigation," Gastrointestinal Endoscopy, vol. 50, no. 2, pp. 152-158, 1999.

[38] U. Heudorf, H. Hofmann, G. Kutzke et al., "Hygiene beim endoskopieren in klinik und praxis, 2003-ergebnisse der infektionshygienischen Überwachung der endoskopie-einrichtungen in Frankfurt am main durch das gesundheitsamt," Zeitschrift für Gastroenterologie, vol. 42, pp. 669-676, 2004.
[39] O. Leiß, L. Bader, and M. Mielke, "Exner M. 5 Jahre Empfehlungen der Kommission für Krankenhaushygiene zur EndoskopAufbereitung-Blick zurück und Blick nach vorn," Bundesgesundheitsbl, Gesundheitsforsch, Gesundheitsschutz, vol. 51, pp. 211-220, 2008.

[40] F. M. Moses and J. Lee, "Surveillance cultures to monitor quality of gastrointestinal endoscope reprocessing," American Journal of Gastroenterology, vol. 98, no. 1, pp. 77-81, 2003.

[41] L. F. Muscarella, "Current instrument reprocessing practices. Results of a national survey," Gastroenterology Nursing, vol. 24, no. 5, pp. 253-260, 2001.

[42] G. Spinzi, R. Fasoli, R. Centenaro, G. Minoli, and The SIED Lombardia Working Group, "Reprocessing in digestive endoscopy units in Lombardy: results of a regional survey," Digestive and Liver Disease, vol. 40, no. 11, pp. 890-896, 2008.

[43] K. M. Taylor, K. Arajs, T. Rouse, and A. W. Harris, "Prospective audit of colonoscopy quality in Kent and Medway, UK," Endoscopy, vol. 40, no. 4, pp. 291-295, 2008.

[44] A. Tunuguntla and M. J. Sullivan, "Monitoring quality of flexible endoscope disinfection by microbiologic surveillance cultures," Tennessee Medicine, vol. 97, no. 10, pp. 453-456, 2004.

[45] L. Bader, G. Blumenstock, B. Birkner et al., "HYGEA (hygiene in der gastroenterologie-endoskop-aufbereitung): studie zur qualität der aufbereitung von flexiblen endoskopen in klinik und praxis," Zeitschrift für Gastroenterologie, vol. 40, pp. 157-170, 2002.

[46] R. G. Kaczmarek, R. M. Moore, J. McCrohan et al., "Multi-state investigation of the actual disinfection/sterilization of endoscopes in health care facilities," American Journal of Medicine, vol. 92, no. 3, pp. 257-261, 1992.

[47] KRINKO, "Anforderungen an die hygiene bei der aufbereitung flexibler endoskope und endoskopischen zusatzinstrumentariums. Empfehlung der kommission für krankenhaushygiene und infektionsprävention beim Robert Koch-Institut," Bundesgesundheitsbl, Gesundheitsforsch, Gesundheitsschutz, vol. 45, pp. 395-411, 2002.

[48] Voraussetzungen gemäß x 135 Abs. 2 SGB V zur Ausführung und Abrechnung von koloskopischen Leistungen (Qualitätssicherungsvereinbarung zur Koloskopie) vom 20. 9. 2002. Deutsches Ärzteblatt 2002, 99: C2126-C2128 Neufassung der, Vereinbarung gemäß x 135 Abs. 2 SGB V zur Ausführung und Abrechnung von koloskopischen Leistungen', vom 24. Juli 2006. Deutsches Ärzteblatt, 103: A2892-A2896, 2006.

[49] A. Jemal, R. Siegel, E. Ward et al., "Cancer statistics, 2008," Cancer Journal for Clinicians, vol. 58, no. 2, pp. 71-96, 2008.

[50] RKI Krebs in Deutschland 2003-2004, "Häufigkeiten und Trends. 6. überarbeitete Auflage," 2008, http://www.rki.de/cln_ 100/nn205770/DE/Content/GBE/Gesundheitsberichtersattung/GBEDownloadsB/KID2008,templateId=raw,property=publicationFile.pdf/KID2008.pdf.

[51] F. Citarda, G. Tomaselli, R. Capocaccia, S. Barcherini, and M. Crespi, "Efficacy in standard clinical practice of colonoscopic polypectomy in reducing colorectal cancer incidence," Gut, vol. 48, no. 6, pp. 812-815, 2001.

[52] G. Flatten, "Krebsfrüherkennung-sekundäre Prävention von Malignomen," in Krankheitsverhütung und FrüherkennungHandbuch der Prävention, P. Allhoff, G. Flatten, and U. Laaser, Eds., pp. S427-S436, Springer, Berlin, Germany, 1993.

[53] B. Levin, D. A. Lieberman, B. McFarland et al., "Screening and surveillance for the early detection of colorectal cancer 
and adenomatous polyps, 2008: a joint guideline from the American Cancer Society, the US multi-society task force on colorectal cancer, and the American College of Radiology," Gastroenterology, vol. 134, no. 5, pp. 1570-1595, 2008.

[54] U. A. Marbet, P. Bauerfelnd, J. Brunner, G. Dorta, J. J. Valloton, and F. Delcò, "Colonoscopy is the preferred colorectal cancer screening method in a population-based program," Endoscopy, vol. 40, no. 8, pp. 650-655, 2008.

[55] A. D. Muller and A. Sonnenberg, "Prevention of colorectal cancer by flexible endoscopy and polypectomy. A case-control study of 32, 702 veterans," Annals of Internal Medicine, vol. 123, no. 12, pp. 904-910, 1995.

[56] R. A. Smith, V. Cokkinides, and O. W. Brawley, "Cancer screening in the United States, 2008: a review of current American Cancer Society guidelines and cancer screening issues," Cancer Journal for Clinicians, vol. 58, no. 3, pp. 161-179, 2008.

[57] L. G. van Rossum, A. F. van Rijn, R. J. Laheij et al., "Random comparison of guaiac and immunochemical fecal occult blood tests for colorectal cancer in a screening population," Gastroenterology, vol. 135, no. 1, pp. 82-90, 2008.

[58] J. M. Wilson and G. Jungner, Principles and Practice of Screening for Disease, World Health Organisation, Geneva, Switzerland, 1968.

[59] S. J. Winawer, A. G. Zauber, M. N. Ho et al., "Prevention of colorectal cancer by colonoscopic polypectomy. The National Polyp Study Workgroup," The New England Journal of Medicine, vol. 329, pp. 1977-1981, 1993.

[60] G. P. Young, P. Rozen, and B. Levin, Eds., Prevention and Early Detection of Colorectal Cancer, WB Saunders Company, London, UK, 1996.

[61] A. Sonnenberg, F. Delcò, and J. Inadomi, "Cost-effectiveness of colonoscopy in screening for colorectal cancer," Annals of Internal Medicine, vol. 135, aricle 218, 2001.

[62] A. Sonnenberg, F. Delcò, and J. Inadomi, "Cost-effectiveness of colonoscopy in screening for colorectalcancer," Annals of Internal Medicine, vol. 133, no. 8, pp. 573-584, 2000.

[63] U. Mansmann, A. Crispin, V. Hentschel et al., "Bilanz der qualitätssicherung ambulanter Koloskopien nach 245, 000 untersuchungen," Deutsches Ärzteblatt, vol. 105, no. 24, pp. 434-440, 2008.

[64] A. Crispin, B. Birkner, A. Munte, G. Nusko, and U. Mansmann, "Process quality and incidence of acute complications in a series of more than 230, 000 outpatient colonoscopies," Endoscopy, vol. 41, no. 12, pp. 1018-1025, 2009.

[65] E. H. Buchholz, Unser Gesundheitswesen-Ein Einführender Überblick Zum Gesundheitswesen in der Bundesrepublik Deutschland, Springer, Heidelberg, Germany, 1988.

[66] J. Alber, Das Gesundheitswesen der Bundesrepublik Deutschland-Entwicklung, Struktur und Funktionsweise, Campus, Frankfurt, Germany, 1992.

[67] F. Beske, T. Drabinski, and U. Golbach, Leistungskatalog des Gesundheitswesens Im Internationalen Vergleich-Eine Analyse Von 14 Ländern. Band I: Struktur, Finanzierung und Gesundheitsleistungen, vol. 104 of Fritz Beske Institut für GesundheitsSystem-Forschung Kiel, Schmidt \& Klaunig, 2005.

[68] D. B. Nelson, W. R. Jarvis, W. A. Rutala et al., "Multi-society guideline for reprocessing flexible gastrointestinal endoscopes," Infection Control and Hospital Epidemiology, vol. 24, no. 7, pp. 532-537, 2003.
[69] F. M. Moses and J. S. Lee, "Current GI endoscope disinfection and QA practices," Digestive Diseases and Sciences, vol. 49, pp. 1791-1797, 2004.

[70] C. Wendt, "Compliance with infection control guidelines," Bundesgesundheitsblatt, Gesundheitsforschung, Gesundheitsschutz, vol. 47, no. 4, pp. 329-333, 2004.

[71] U. Heudorf, "Compliance mit hygienischen rechtsvorschriften und richtlinien in medizinischen einrichtungen-aus sicht eines gesundheitsamtes," Hygiene \& Medizin, vol. 30, pp. 292-297, 2005.

[72] E. Fröhlich, R. Muller, J. M. Kimmig, and G. Funke, "Qualitätssicherungsvereinbarung koloskopie" der kassenärztlichen vereinigung nord-württemberg” 2003 bis 2007," Zeitschrift für Gastroenterologie, vol. 47, pp. 203-208, 2009.

[73] QSHE, "Pilotprojekt der kassenärztlichen vereinigung bayerns," Gastro Nachrichten Nr 37 1/2003, Seite 6-7.

[74] E. Fröhlich, R. Muller, and O. Leiß, "Effect of quality assessment assurance in 2002 (before starting the German colorectal cancer screening programme by colonoscopy) on the quality of reprocessing of flexible endoscopes-a nationwide analysis," Zeitschrift für Gastroenterologie, vol. 47, no. 11, pp. 1137-1144, 2009.

[75] B. Zühlsdorf and G. Kampf, "Evaluation of the effectiveness of an enzymatic cleaner and glutaraldehyde-based disinfectant for chemothermal processing of flexible endoscopes in washerdisinfectors in accordance with prEN ISO 15883," Endoscopy, vol. 38, no. 6, pp. 586-591, 2006.

[76] A. J. Buss, M. H. Been, R. P. Borgers et al., "Endoscope disinfection and its pitfalls-requirement for retrograde surveillance cultures," Endoscopy, vol. 40, no. 4, pp. 327-332, 2008. 


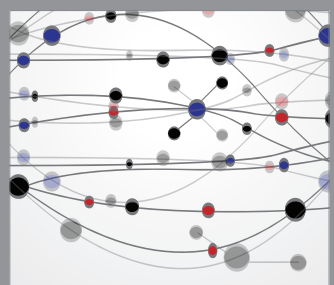

The Scientific World Journal
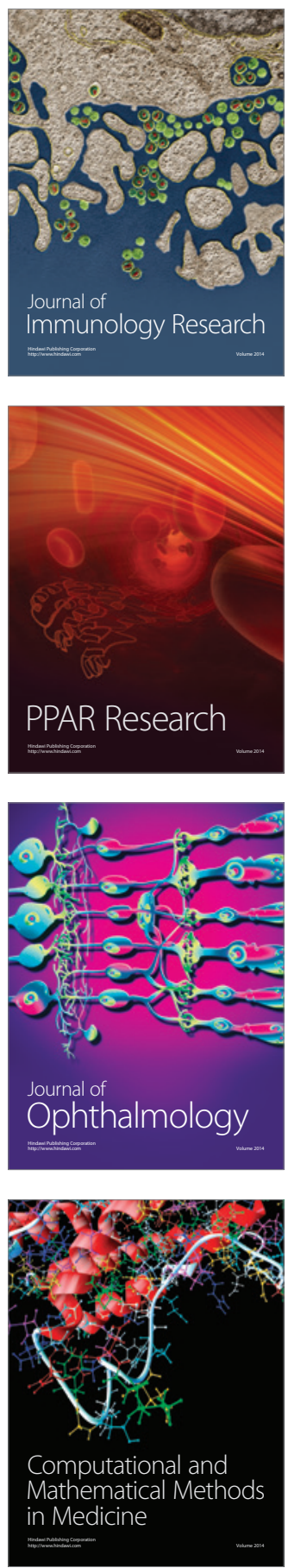

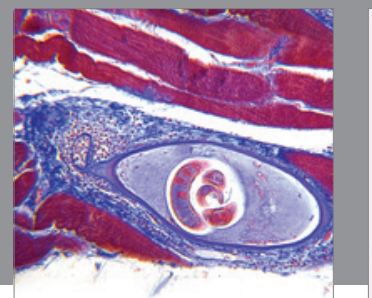

Gastroenterology

Research and Practice
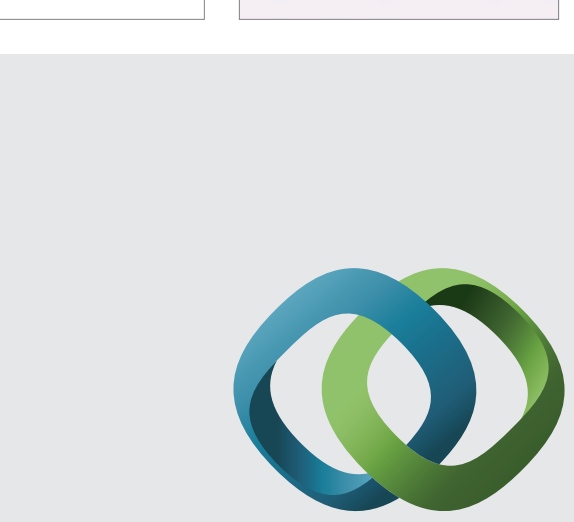

\section{Hindawi}

Submit your manuscripts at

http://www.hindawi.com
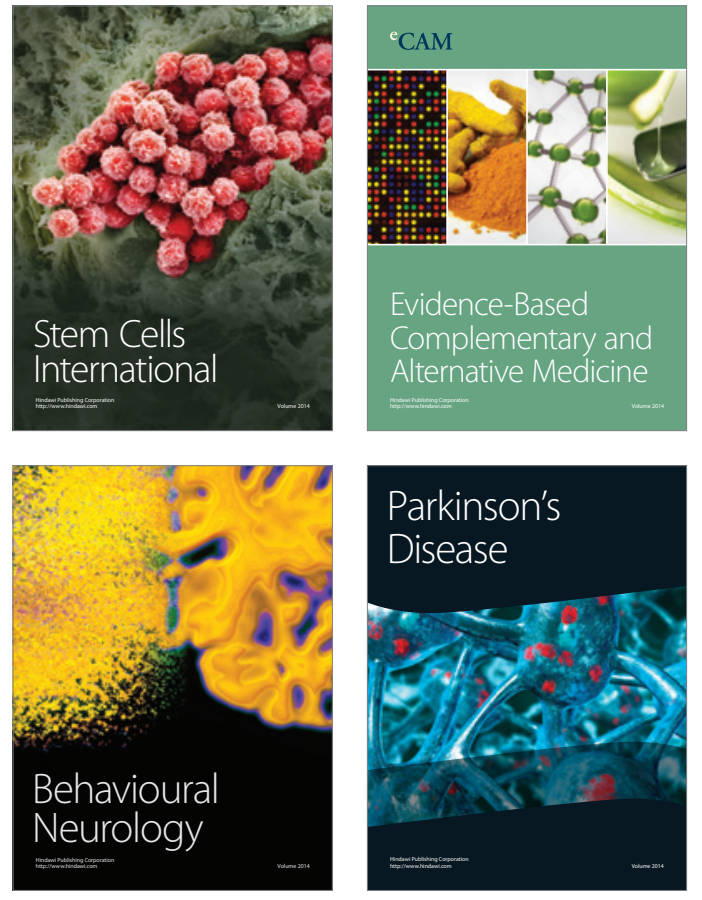
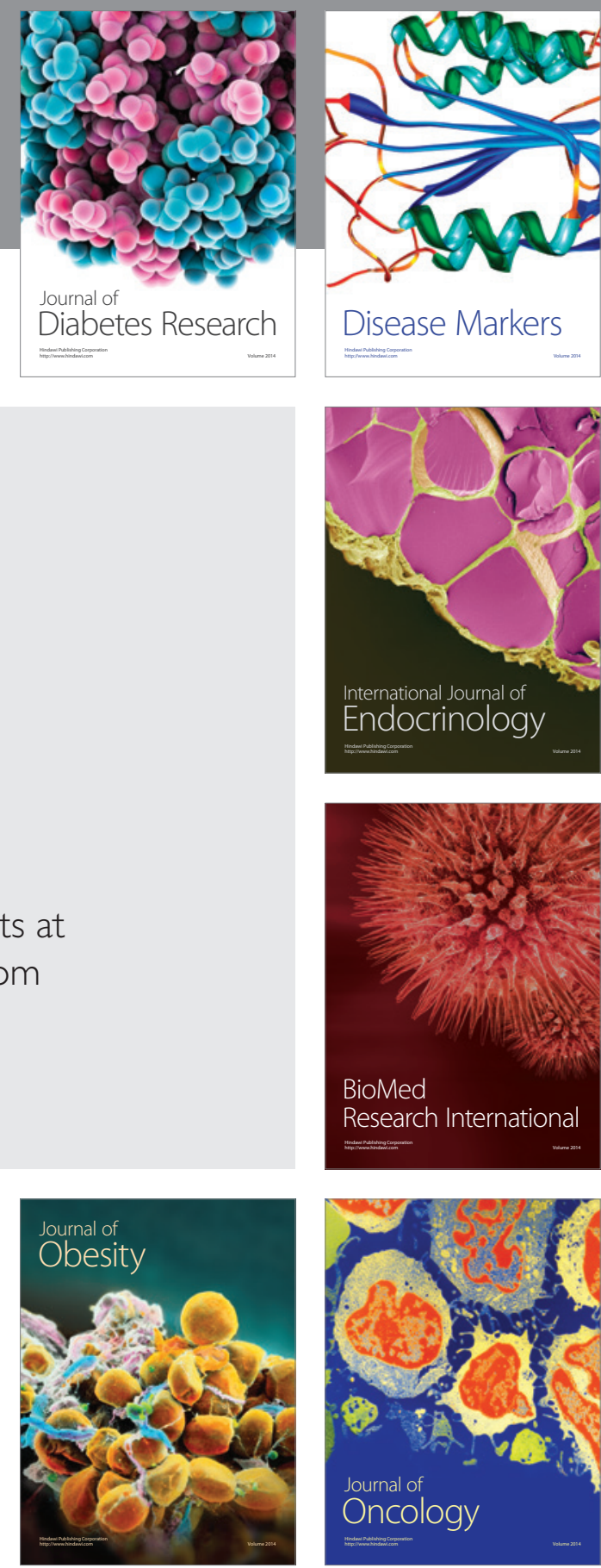

Disease Markers
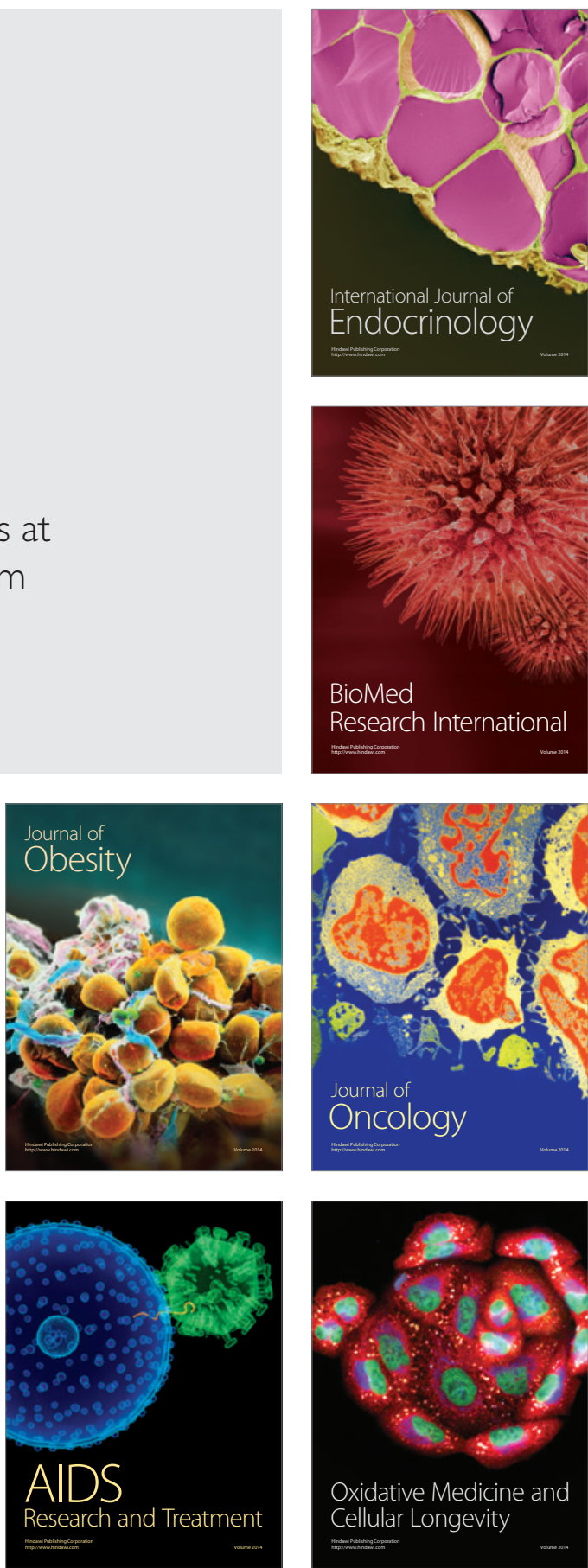